\title{
Swinging From Hypothyroidism to Hyperthyroidism: A Rare Entity Yet With Different Pathophysiology (Case-Based Review)
}

\author{
Maria Faraz
}

\begin{abstract}
Although rare but some patients developed hyperthyroidism preceded by hypothyroidism after being treated with levothyroxine. I reported a 35-year-old male who developed hyperthyroidism after getting treated with levothyroxine for hypothyroidism. Patient showed evident clinical and biochemical hypothyroidism with TSH of $175 \mu \mathrm{U} / \mathrm{mL}$ and free T4 of $2.7 \mathrm{pmol} / \mathrm{L}$, and started on levothyroxine. Levothyroxine was stopped after 3 years as he had become euthyroid. However, over a period of 1 year, he gradually had developed thyrotoxic state with TSH less than $0.01 \mu \mathrm{U} / \mathrm{mL}$ and $\mathrm{T} 4$ of $26 \mathrm{pmol} / \mathrm{L}$ and clinical symptoms of thyrotoxicosis. He has now started on methimazole 5 $\mathrm{mg}$ /day and will be followed up in 6 months. Therefore, physicians are required to have a frequent assessment of thyroid function test to identify the occurrence of this rare entity of swinging from hypothyroidism to hyperthyroidism in order to initiate proper treatment.
\end{abstract}

Keywords: Hypothyroidism; Hyperthyroidism; Levothyroxine

\section{Introduction}

Development of hypothyroidism following primary hypothyroidism is rare; however, in some circumstance, there is a switch in patients with primary hypothyroidism into thyrotoxicosis after being treated with levothyroxine [1]. This is a case in which patient with hypothyroidism on levothyroxine spontaneously develops hyperthyroidism after stopping the medicine. Here I also discuss a mechanism of situation oscillating between hypothyroidism and hyperthyroidism.

\section{Case Report}

A 35-year-old patient presented in October 2011 with clinical

Manuscript accepted for publication August 19, 2016

Department of Endocrinology and Metabolism, Hamilton General Hospital, Ontario, Canada. Email: maria.faraz01@gmail.com

doi: http://dx.doi.org/10.14740/jem370w and biochemical hypothyroidism with no preceding symptoms of hyperthyroidism. His TSH was $175 \mu \mathrm{U} / \mathrm{mL}$ with free T4 of $2.7 \mathrm{pmol} / \mathrm{L}$. On the basis of clinical and biochemical evidence, the patient started on levothyroxine. On subsequent follow-up visits, patient's symptoms improved along with biochemical evidence and we started to cut down levothyroxine gradually from 0.25 to $0.137 \mathrm{mg}$ daily and levothyroxine was stopped in 2015 as he had become euthyroid.

However, over the period of 1 year, the patient developed symptoms of hyperthyroidism, i.e. increased nervousness, palpitation, weight loss of 10 pounds in 1 month with a normal appetite, heat intolerance, dry eyes and brittle nails.

Biochemically, his TSH was less than $0.01 \mu \mathrm{U} / \mathrm{mL}$, T3 was $11.3 \mathrm{pmol} / \mathrm{L}$, free T4 was $26 \mathrm{pmol} / \mathrm{L}$, TPO antibodies were less than 600 and thyroglobulin antibodies were 557 (elevated). On the basis of clinical and biochemical hyperthyroidism, patient started on anti-thyroid drug and will be followed up. Patient's investigations are summarized in Table 1.

\section{Discussion}

TSAb and hyperthyroidism develop unexpectedly in some patients with hypothyroidism that is caused by TBAb. This shift in thyroid function occurs only rarely in a disease that is, in itself, rare [1]. Takasu and Matsushita reported the LT4-associated increase in TSAb and the development of hyperthyroidism in hypothyroid patients [2]. In another patient, who swung between hypo- and hyperthyroidism, TSAb activity was first detected after LT4 therapy for hypothyroidism [3]. Therefore, on the basis of these reports, it is assumed that in a small group of people, there is an increase in ongoing thyroid autoantibody responses as well as the de novo appearance of TSAb in HT patients with or without TBAb [4].

Sandra and Basil suggested the hypothesis that levothyroxine leads to increase in TSAb based on the mechanism involving dendritic cell and T-regulatory cell [4].

A brief review of the dendritic cell and T-regulatory cell and their interaction is described. Dendritic cells are the antigen-presenting cells of the immune system. Their main function is to process antigen material and present it on the cell surface to the $T$ cells of the immune system. Whereas the primary function of T-regulatory cells was originally defined as prevention of autoimmune diseases by maintaining self- 
Table 1. Summary of Investigations

\begin{tabular}{llll}
\hline Date & TSH $(\boldsymbol{\mu U} / \mathbf{m L})$ & Free T4 $(\mathbf{p m o l} / \mathbf{L})$ & Levothyroxine \\
\hline October 2011 & 175 & 2.7 & Started on $0.25 \mathrm{mg}$ \\
January 2012 & 25 & 18 & $0.25 \mathrm{mg}$ \\
February 2012 & 0.19 & 21 & $0.15 \mathrm{mg}$ \\
\hline January 2013 & 0.12 & 24 & $0.137 \mathrm{mg}$ \\
March 2014 & 0.02 & 22 & $0.137 \mathrm{mg}$ \\
February 2015 & 0.24 & Normal & Stopped \\
May 2015 & 0.07 & Normal & None \\
\hline July 2015 & 0.01 & Normal & \\
\hline November 2015 & Less than 0.01 & Normal with 8.1 FT3 & Started on methimazole $5 \mathrm{mg}$ \\
\hline May 2016 & Less than 0.01 & 26 & \\
\hline
\end{tabular}

tolerance [5].

Dedecjus and Stasiolek in their study provide an evidence that the thyrometabolic status has an influence on the phenotype and function of human peripheral blood dendritic cells and increase in co-stimulatory molecules to initiate antibody production [6].

Polarized dendritic cells lead to impaired functional Tregulatory changes that potentially permit the emergence of pathogenic autoantibodies [7] such as TSAb. It should be appreciated that the range of thyroid hormones is narrower for a particular individual than the normal range for a population [8]. Consequently, despite the goal of treatment to "normalize" thyroid hormone levels, serum T4 may be elevated for a particular individual, and the resulting hyperthyroidism will adversely impact dendritic cell and T-regulatory function [4], therefore, leading to a switch from hypothyroidism to hyperthyroidism.

\section{Conclusion}

Although flipping from hypothyroidism to hyperthyroidism is an unusual presentation, frequent assessment of thyroid function in patients with clinical symptoms of thyroid dysfunction along with measurement of TBAb and TSAb is contributory in identifying this rare clinical entity of fluctuating hypothyroidism and hyperthyroidism and initiating appropriate therapy.

\section{References}

1. Lewandowski K, Dabrowska K, Makarewicz J, Lewinski A. Pendulum swings from hypo- to hyperthyroidism: thyrotoxicosis after severe hypothyroidism following neck irradiation in a patient with a history of Hodgkin's lymphoma. Thyroid Res. 2016;9:1.

2. Takasu N, Matsushita M. Changes of TSH-Stimulation Blocking Antibody (TSBAb) and Thyroid Stimulating Antibody (TSAb) Over 10 Years in 34 TSBAb-Positive Patients with Hypothyroidism and in 98 TSAb-Positive Graves' Patients with Hyperthyroidism: Reevaluation of TSBAb and TSAb in TSH-Receptor-Antibody (TRAb)Positive Patients. J Thyroid Res. 2012;2012:182176.

3. Kraiem Z, Baron E, Kahana L, Sadeh O, Sheinfeld M. Changes in stimulating and blocking TSH receptor antibodies in a patient undergoing three cycles of transition from hypo to hyper-thyroidism and back to hypothyroidism. Clin Endocrinol (Oxf). 1992;36(2):211-214.

4. McLachlan SM, Rapoport B. Thyrotropin-blocking autoantibodies and thyroid-stimulating autoantibodies: potential mechanisms involved in the pendulum swinging from hypothyroidism to hyperthyroidism or vice versa. Thyroid. 2013;23(1):14-24.

5. Corthay A. How do regulatory T cells work? Scand J Immunol. 2009;70(4):326-336.

6. Dedecjus M, Stasiolek M, Brzezinski J, Selmaj K, Lewinski A. Thyroid hormones influence human dendritic cells' phenotype, function, and subsets distribution. Thyroid. 2011;21(5):533-540.

7. Mao C, Wang S, Xiao Y, Xu J, Jiang Q, Jin M, Jiang X, et al. Impairment of regulatory capacity of CD4+CD25+ regulatory $\mathrm{T}$ cells mediated by dendritic cell polarization and hyperthyroidism in Graves' disease. J Immunol. 2011;186(8):4734-4743.

8. Andersen S, Pedersen KM, Bruun NH, Laurberg P. Narrow individual variations in serum T(4) and T(3) in normal subjects: a clue to the understanding of subclinical thyroid disease. J Clin Endocrinol Metab. 2002;87(3):1068-1072. 